\title{
Helen Salisbury: Planning for the peak
}

\author{
Helen Salisbury GP \\ Oxford
}

This week we've been climbing a very steep learning curve about coronavirus infection. With so many unknowns I feel up in the air, as though my toes are barely touching the safe ground of my medical training. I'm experienced, fairly confident, and-until this week-not in the habit of taking home worries about my patients. Now, the more I read, the less certain I feel about some of my advice. When "outdated" refers to guidance based on China's experience and published a month ago, being up to date takes on a whole new meaning.

Although a few patients call us for advice at the first sign of symptoms, many try hard to manage at home without contacting medical services. Some ring us a week or more into their illness when they're over the worst, and I try to be reassuring about prognosis. "Safety netting" has never been more important, particularly the instruction to call for help if they feel more unwell or breathless. Then, having read about late deteriorations or about low oxygen levels manifesting as confusion with no subjective sensation of breathlessness, I worry anew.

We've set up a system to proactively contact all patients we're concerned about, at 24 or 48 hour intervals. I'm currently trying to source more oxygen saturation probes so that we can lend them out for home monitoring. Questions remain about decontamination (although it seems that readings are accurate through a latex glove), but I hope that we'll have solved them by the time you read this.
Changes are happening quickly, all over the NHS. One of the most heartening is the melting of ego and the overturning of hospital hierarchies. Surgeons, relieved of their elective lists, volunteer for nursing shifts in intensive care, and consultants slide back down the career ladder to become juniors in unfamiliar acute specialties. When this is all over, will we have learnt a kinder and more flexible way of working together? In general practice, some of us are experiencing impostor syndrome: the real doctors are at the front line in the hospital, or they're at "hot hubs" and palliative care visiting services in the community. Reading gruelling accounts of 12 hour shifts in intensive care makes me grateful for the relative safety of my surgery.

This may all change, but for now we're continuing to provide ordinary care in extraordinary times. People still need treatment for asthma, diabetes, depression, and hypertension. They still need diagnosis and speedy referral to exclude cancer. More than ever, patients need reassurance and continuity from their GP surgery and to hear us say, "We're still here, we will still care for you, and we'll make sure your medicines reach you. You're OK, we've got this-just stay home."

Competing interests: See www.bmj.com/about-bmj/freelance-contributors. Provenance and peer review: Commissioned; not externally peer reviewed. Published by the BMJ Publishing Group Limited. For permission to use (where not already granted under a licence) please go to http://group.bmj.com/group/rights-licensing/ permissions 